\title{
Robert Felkin MD (1853-1926) and Caesarean delivery in Central Africa (1879)
}

\author{
Peter M Dunn
}

It was as a pupil at Wolverhampton Grammar School $^{1}$ that Robert William Felkin met the explorer David Livingstone, who inspired him with his tales of Africa. And when he met A M Mackay, a medical missionary from Uganda, in London in 1877 at the age of 24, he became determined to visit Africa.

By 1875 he had become a medical student at Edinburgh University, but before completing his training, he was sent to Uganda in 1878 by the Church Missionary Society. He travelled up the Nile to Khartoum, where he met General Gordon, and then on through what was then wild and unmapped country to the Great Lakes. There he met Emin Pasha, the Governor of the Equatorial Province, and was presented to King M'tesa, whose personal physician he became in 1879 . When a Muslim anti-missionary movement threatened the lives of his fellow Christians, Felkin warned the King that, should any harm come to them, a great disaster would befall his people. As a sign he foretold that the sun would be darkened; in due course the anticipated eclipse occurred and Felkin was established as a great "medicine man." During his stay in Uganda he studied the local diseases and also undertook anthropological measurements of the pygmies. Of particular interest, though, were his studies on childbirth.

In 1880 he returned down the Nile and on to England in the company of envoys of King M'tesa to Queen Victoria. Later that year he returned to Africa, travelling widely but spending most of his time in Zanzibar where he actively campaigned against the slave trade. In 1881 he returned to Edinburgh to complete his medical studies (LRCP, LRCS,Ed, 1884). While still a medical student he became a Fellow of the Royal Society of Edinburgh, a Fellow of the Royal Geographical Society, a member of the Anthropological Institute of Great Britain and a corresponding Fellow of the Berlin Anthropological Society. As a final year student he gave a lecture to the Edinburgh Obstetrical Society on 9 January 1884 entitled "Notes on Labour in Central Africa." 2 It is from this lecture that the following fascinating account of a Caesarean delivery is taken:

\section{Health \\ Bristol University \\ Southmead Hospital \\ Bristol BS 10 5NB \\ P M Dunn}

Department of Child

Correspondence to: Professor Peter Dunn.

\section{On Caesarean section}

"So far as I know, Uganda is the only country in Central Africa where abdominal section is practised with the hope of saving both mother and child. The operation is performed by men, and is sometimes successful; at any rate, one case came under my observation in which both survived. It was performed in 1879 at Kahura. The patient was a fine healthy-looking young woman of about twenty years of age. This was her first pregnancy ... The woman lay upon an inclined bed, the head of which was placed against the side of the hut. She was liberally supplied with banana wine, and was in a state of semi-intoxication. She was perfectly naked. A band of mbuga or bark cloth fastened her thorax to the bed, another band of cloth fastened down her thighs, and a man held her ankles. Another man, standing on her right side, steadied her abdomen (fig 1). The operator stood, as I entered the hut, on her left side, holding his knife aloft with his right hand, and muttering an incantation. This being done, he washed his hands and the patient's abdomen, first with banana wine and then with water. Then, having uttered a shrill cry, which was taken up by a small crowd assembled outside the hut, he proceeded to make a rapid cut in the middle line, commencing a little above the pubes, and ending just below the umbilicus. The whole abdominal wall and part of the uterine wall were severed by this incision, and the liquor amnii escaped; a few bleeding-points in the abdominal wall were touched with a red-hot iron by an assistant. The operator next rapidly finished the incision in the uterine wall; his assistant held the abdominal walls apart with both hands, and as soon as the uterine wall was divided he hooked it up also with two fingers. The child was next rapidly removed, and given to another assistant after the cord had been cut, and then the operator, dropping his knife, seized the contracting uterus with both hands and gave it a squeeze or two. He next put his right hand into the uterine cavity through the incision, and with two or three fingers dilated the cervix uteri from within outwards. He then cleared the uterus of clots and the placenta, which had by this time become detached, removing it through the abdominal wound. His assistant endeavoured, but not very successfully, to prevent the escape of the intestines through the wound. The red-hot 


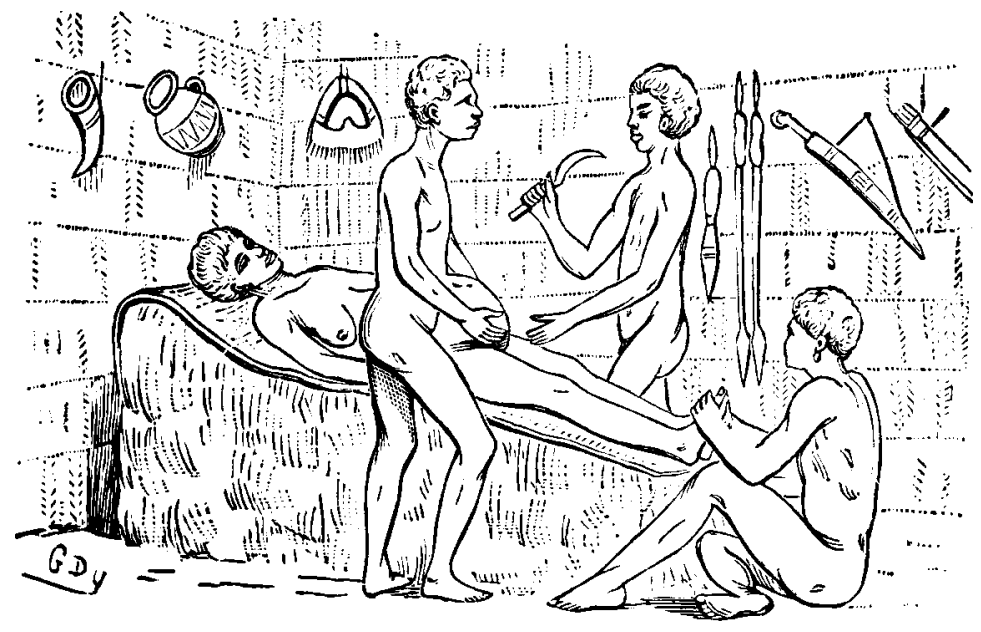

Figure 1 Caesarean delivery in Uganda, 1879.

iron was next used to check some further haemorrhage from the abdominal wound, but I noticed that it was very sparingly applied. All this time the chief "surgeon" was keeping up firm pressure on the uterus, which he continued to do till it was firmly contracted. No sutures were put into the uterine wall. The assistant who had held the abdominal walls now slipped his hands to each extremity of the wound, and a porous grass mat was placed over the wound and secured there. The bands which fastened the woman down were cut, and she was gently turned to the edge of the bed, and then over into the arms of assistants, so that the fluid in the abdominal cavity could drain away on to the floor. She was then replaced in her former position, and the mat having been removed, the edges of the wound, i.e. the peritoneum, were brought into close apposition, seven thin iron spikes, well polished, like acupressure needles, being used for the purpose, and fastened by string made from bark cloth. A paste prepared by chewing two different roots and spitting the pulp into a bowl was then thickly plastered over the wound, a banana leaf warmed over the fire being placed on the top of that, and, finally, a firm bandage of mbugu cloth completed the operation.

Until the pins were placed in position the patient had uttered no cry, and an hour after the operation she appeared to be quite comfortable. Her temperature, as far as I know, never rose above $99.6^{\circ} \mathrm{F}$, except on the second night after the operation, when it was $101^{\circ} \mathrm{F}$, her pulse being 108 .

The child was placed to the breast two hours after the operation, but for ten days the woman had a very scanty supply of milk, and the child was mostly suckled by a friend. The wound was dressed on the third morning, and one pin was then removed. Three more were removed on the fifth day, and the rest on the sixth. At each dressing fresh pulp was applied, and a little pus which had formed was removed by a sponge formed of pulp. A firm bandage was applied after each dressing. Eleven days after the operation the wound was entirely healed, and the woman seemed quite comfortable. The uterine discharge was healthy. This was all I saw of the case, as I left on the eleventh day. The child had a slight wound on the right shoulder; this was dressed with pulp, and healed in four days."

After qualifying Felkin pursued his medical studies in Heidelberg and Marburg, receiving an MD there in 1885 . He was able to give advice to $\mathrm{H}$ M Stanley on the route to follow in his mission to rescue Emin Pasha, beleaguered by the forces of the Mahdi who had captured Khartoum and killed Gordon in January 1885.

Back in the UK he was appointed lecturer in tropical medicine to the Edinburgh Medical School, a post which he held from 1890 to 1900. During that period he also made further visits to Africa, practised privately, and published a several books on Africa, on tropical diseases and their geographical distribution.

In 1914 Felkin was in Germany at the outbreak of the Great War but was able to get back to the UK after a few weeks and for a time served with the National Guard. But in 1916 his health broke down as the result of malaria and other diseases contracted in Africa and he decided to emigrate to New Zealand. He spent the remainder of his life there, practising as a consulting physician between bouts of ill health. His strong personality, clinical acumen, combined with a kind and generous nature brought him patients from far afield, including Australia. On 28 December 1926, he died at Havelock North in the North Island. He was survived by his wife, a daughter, and two sons.

\footnotetext{
1 Anonymous. Robert William Felkin, MD, FRS. Ed. BMf1927;i:309.

2 Felkin RW. Notes on labour in Central Africa. Edin Med $\mathcal{F}$ 1884;29:922-30.
} 